\title{
LAS MIGRACIONES INTERNACIONALES Y LA SEGURIDAD MULTIDIMENSIONAL EN TIEMPOS DE LA GLOBALIZACIÓN*
}

\author{
INTERNATIONAL MIGRATIONS AND MULTIDIMENSIONAL \\ SECURITY IN TIMES OF GLOBALIZATION
}

\author{
Guillermo Bravo Acevedo**
}

\begin{abstract}
Este trabajo tiene como objetivo central reflexionar respecto del tema de las migraciones internacionales en el actual contexto de la globalización y mundialización de la economía, analizando antecedentes que permitan explicar por qué dichas migraciones han dejado de tener un carácter económico de subsistencia y se han convertido en una amenaza para la seguridad de los países receptores de migrantes.

El corpus del texto se referirá, primero, a la globalización y mundialización económica describiendo sus características, tratando luego la situación de las migraciones internacionales y las transformaciones que han experimentado hasta los años del presente siglo XXI, para finalizar destacando que los cambios que se han producido en el mundo globalizado han acentuado aún más la relación del binomio migraciones-seguridad.
\end{abstract}

Palabras clave: Migraciones internacionales, seguridad multidimensional, globalización.

This paper has as a main objective to reflect on international migrations in the current context of globalization and globalized economy, analyzing antecedents that contribute to explain why such migrations have stopped having a merely economic character of subsistence and have become a multidimensional treat for the those countries that receive migrants.

The body of the text will refer, first, to globalization and economic globalization describing their characteristics, then treating the situation of international migration and the changes that they have experienced until the years of this century, finally noting that the changes that have produced in the globalized world have accentuated even more the relationship between migrations and security.

Key words: International migrations, multidimensional security, globalization.

\section{Introducción}

La globalización y la mundialización económica actuales han generado cambios radicales que han impactado significativamente el orden internacional. Dichos impactos no solo se han manifestado en el área económica, comercial o productiva, sino que también han afectado a las relaciones sociales, la cultura, la política nacional y las relaciones internacionales, porque el espacio transnacional se ha constituido en el marco de la globalización (Ellwood 2007).

El mundo moderno y contemporáneo del siglo XXI, al transformarse en globalizado, ha sumado a sus tradicionales conflictos nuevos problemas, cuyo perfil atenta contra la seguridad, el desarrollo de los Estados y su estabilidad democrática. Estos nuevos problemas han transformado el carácter tradicional de la seguridad, puesto que las amenazas ya no se definen solo en términos militares (Battaglino 2008), sino que ha asumido un carácter multidimensional admitiendo que hay otras amenazas, como las económicas, las medioambientales y las migraciones masivas (Font y Ortega 2012). Por su parte, en la Conferencia Especial sobre Seguridad, de México 2003, se reconoció que los nuevos problemas de la región se denominan en conjunto "amenazas multidimensionales", acordándose que "Nuestra nueva concepción de la seguridad en el Hemisferio es de alcance multidimensional, incluye las amenazas tradicionales y las nuevas amenazas..." (Organización de Estados Americanos [OEA] (2003:2).

Años antes de esta declaración, Vilanova proponía denominar estas amenazas "factores de riesgo" porque en su concepto amenazas como el narcotráfico, la ecología, las migraciones, el terrorismo

\footnotetext{
* Resultado del Programa Estudios sobre Seguridad y Globalización y su línea de investigación asociada: Globalización y sus efectos en la Seguridad.

** Academia Nacional de Estudios Políticos y Estratégicos, Santiago, Chile. Correo Electrónico: gbravo@anepe.cl
}

Recibido: 22 de noviembre de 2014. Aceptado: 15 de febrero de 2015. 
y los fundamentalismo no eran nuevas (Vilanova 1997). Y respecto de las migraciones acotaba que desde la década del 60 ya estaban presentes en Europa y que lo único nuevo que se presentaba era la combinación del fenómeno migratorio “....con el paro estructural que generan nuestras sociedades, allá donde coinciden bolsa de paro con la población inmigrada o sus descendientes... Eso sí es un cóctel que cualitativamente, y no cuantitativamente, se ha vuelto más peligroso" (Vilanova 1997:37).

Por su parte, Pía Lombardo al referirse al concepto multidimensional de seguridad afirma que “...no hace más que agrupar bajo un mismo término incluyente todos los elementos que son abordados en distintos contextos y con fundamentos teóricos disímiles" (Lombardo 2006:71).

La concepción de la seguridad bajo estos términos permitió incorporar al conjunto de amenazas aspectos sociales, económicos, ambientales, políticos y militares. Con referencia a los temas que son relevantes para la propia seguridad de los Estados, Battaglino señala que "Desafíos no tradicionales, como la degradación ambiental, el bienestar económico, las migraciones, el crimen transnacional, entre otras cuestiones, han sido incorporados a una ampliada agenda de seguridad" (Battaglino 2008:19).

En este contexto, el mundo globalizado integra progresivamente las economías y las sociedades y facilita la migración internacional debido a la libertad de movimiento de las personas, pero al mismo tiempo, provoca una incongruencia porque en términos de globalización la migración se hace cada vez más difícil. Este fenómeno se produce porque las migraciones se encuentran en el escenario de la globalización dentro de un proceso contradictorio, ya que por un lado se liberalizan y desregulan los flujos de capital, mercancías, tecnología e información y, por otro, se refuerzan los controles fronterizos y aumentan las dificultades impuestas a la circulación de las personas y de la fuerza de trabajo (Aliaga Sáez 2012).

Asimismo, un efecto secundario de la globalización se relaciona con el aumento de las actividades transfronterizas ilegales que se manifiesta en la evasión de impuestos, blanqueo de capitales, trata de personas y comercio de sexo y droga (Comisión Mundial sobre la Dimensión Social de la Globalización [CMDSG] 2004).

Estas nuevas condiciones han fomentado la migración irregular; carácter que ha servido de argumento para construir un discurso que considera a las migraciones como un riesgo, una amenaza a la seguridad, y aspecto esencial en la agenda de la estrategia de seguridad de los países, tanto en el plano nacional como internacional.

En esa perspectiva, el objetivo de este trabajo es analizar por qué las migraciones internacionales han dejado de tener un carácter meramente económico, de subsistencia, y se han convertido en un problema para la seguridad interna, estableciendo que la dualidad asumida por el proceso migratorio, de navegar entre la economía y la seguridad, han convertido a los migrantes en personas que se catalogan como mano de obra necesaria para el mercado de trabajo o como peligrosas porque representan una potencial amenaza para la sociedad receptora.

\section{Globalización y mundialización económica}

Cristóbal Colón llegó a las costas de América con el propósito de anexar nuevas tierras a la Corona española y de encontrar un nuevo camino hacia las Indias. Dicha anexión permitió el inicio de un proceso económico de larga duración que, a fines del siglo XX, se conoce con el nombre de globalización.

En efecto, en el siglo XV la política económica que aplicaban las naciones para el desarrollo de la economía era la mercantilista. Esta era una política de carácter proteccionista, cuyos principios establecían que la riqueza de los reinos se basaba en la acumulación de oro, plata y piedras preciosas, por medio del control monopólico del comercio o de la explotación de minas de plata y oro en las colonias, o ambas estrategias simultáneamente (Bravo 2004).

Por esta razón, el impacto de la contribución colombina fue inmediato, porque se inició la expansión de la economía y comenzó a completarse el circuito del comercio mundial. En el siglo XVIII, Adam Smith planteó que el crecimiento económico y la riqueza de las naciones se sostenía en el producto anual del trabajo, agregando a esta tesis central la idea de un orden natural, que es el resultado tanto del interés individual como de la libre empresa, la libre competencia y el libre comercio (Smith 1992). De esta forma, Smith sentó las bases del liberalismo económico.

A mediados del siglo XX, el historiador francés Fernand Braudel (Braudel 1982), tratando de interpretar este proceso, desarrolló el concepto de economía-mundo con el objeto de definir el sistema económico internacional en tiempos del imperio 
español del siglo XVI. A ese proceso se sumó la Revolución Industrial, que junto con la aplicación del liberalismo económico, durante los siglos XIX y XX, dio paso a la consolidación del capitalismo.

A principios del siglo XXI, en plena vigencia del llamado neoliberalismo, diversos autores sostienen que todo análisis que se realice para describir el estado actual del mundo no puede dejar de lado los conceptos de globalización y mundialización económica debido a que consideran que es la fase actual de la evolución del capitalismo (Beck 1998; Castells 2005; Dehesa 2000; Zolo 2000; Trigo y Tremosa 2003).

La globalización, entonces, es el resultado de la evolución histórica de la política económica liberal y del desarrollo capitalista, que hoy está marcado por el sello de la sociedad y economía del conocimiento, por los acuerdos económicos entre los países que guían el crecimiento y por las redes del circuito de comercio mundial.

No obstante, como al capitalismo se han sumado factores de orden internacional, como la creación de un mercado mundial con supresión de barreras aduaneras, la mediación de redes virtuales que permiten la libre circulación y transferencia de capitales, y la puesta en marcha de la economía del conocimiento, o lo que es lo mismo, la economía que invierte en capital humano y social, podríamos preguntarnos ¿qué se debe entender por globalización?

Una definición conceptual establece que la globalización es el "Proceso por el que las economías y mercados, con el desarrollo de las tecnologías de la comunicación, adquieren una dimensión mundial, de modo que dependen cada vez más de los mercados externos y menos de la acción reguladora de los gobiernos" (Diccionario de la Real Academia Española de la Lengua [DRAE] 2014).

Desde el punto de vista histórico, siguiendo la hipótesis de LaCapra de que la historia se encuentra en continuo tránsito o transición (LaCapra 2006) se puede entender la globalización como un proceso que ha implicado un conjunto de cambios observables en el campo político, económico y social, hacia los finales del siglo XX. Como fenómeno histórico de largo plazo, los cambios crearon ciertos lazos comunes o de unión entre las estructuras y los factores políticos, económicos, sociales, culturales y tecnológicos que convirtieron al orden internacional en un mundo interconectado o una aldea global.

En esta perspectiva, se puede decir que la globalización no está limitada solamente a una dimensión económica, sino que su ámbito de acción se extiende, en gran escala, hacia lo político, lo social, lo cultural y lo tecnológico posibilitando espacios de integración activa y formas de cooperación entre Estados, territorios y bloques económicos para fomentar las relaciones comerciales ${ }^{1}$.

De esta forma, la mundialización ha posibilitado la integración progresiva de las economías y de las sociedades y ha permitido observar que el mundo actual también posee otras dimensiones globalizadas, como la globalización política que ha permitido a los Estados instalar instituciones a escala planetaria para dar solución a los temas que afectan a todos los habitantes del planeta.

Otro aspecto de la mundialización se refiere a que las diferencias culturales locales están dando paso a modelos generales dominantes que se extienden por todo el mundo con la dimensión cultural de la globalización. Esto determina que en algunos países se hayan perdido las formas de vida y las costumbres, las identidades y los imaginarios nacionales colectivos (Moneta 2000).

El desarrollo de la tecnología es otra dimensión de la globalización. Definida como el "poderoso $\mathrm{y}$ visible conjunto de tecnologías, productos e industrias nuevas y dinámicas, capaces de sacudir los cimientos de la economía y de impulsar una oleada de desarrollo de largo plazo" (Mendizábal 2010), se debería entender que representa la difusión de la tecnología en el mundo, de las naciones; atravesando fronteras sin importar las características de las naciones o de las culturas a las que llegará y de las transformaciones a que dará lugar. De esta forma, la llamada revolución tecnológica implica a todos los Estados y regiones, pero a la vez produce gran marginación de algunos países, zonas y grupos sociales (Aguirre 2000), debido a que no todos están en el mismo nivel de desarrollo o al alcance de las transformaciones tecnológicas.

La globalización del sector social es uno de los campos en que más ha impactado el proceso de mundialización. Los cambios producidos en la vida personal y social de las personas, las consecuencias que ha tenido en sus condiciones laborales, en sus ingresos y en el marco de la previsión social son variados, pero más allá del mundo del trabajo, la dimensión social de la globalización abarca las cuestiones relativas a la seguridad, la cultura y la identidad, la inclusión o la exclusión social y la cohesión de las familias de las relaciones de sociabilidad y de las sociedades (CMDSG 2004). 
Sin embargo, el impacto que ha ejercido la globalización en los nichos del mercado laboral, en la plataforma del comercio internacional, en la libertad de circulación y en la calidad de vida de la población, tiene una intensidad distinta en función del nivel de desarrollo de las naciones.

Uno de los aspectos en que la globalización económica ha impactado más es el referido a las migraciones internacionales. Según la CEPAL, es un fenómeno multifacético “...que involucra a todos los países y debe ser objeto de diálogo y cooperación internacional, sin que ello implique menoscabo alguno de la soberanía nacional para establecer los marcos legales y políticos sobre migración internacional" (Comisión Económica para América Latina [CEPAL] 2003:249).

Los movimientos de población tienen en la actualidad características más complejas, pues los migrantes internacionales constituyen un grupo humano diverso y heterogéneo y porque además, no solo ha aumentado el número de migrantes sino que también "... ha aumentado asimismo el número de categorías administrativas y legales en las cuales son enmarcados por los gobiernos y organizaciones internacionales" (Sprandel et al 2008:11).

De esta manera, la globalización si bien abrió un campo propicio para la libre circulación de bienes y servicios con la mundialización de la economía e indirectamente abrió mercados de trabajo y espacios de asentamiento que alentaron las migraciones internacionales, al mismo tiempo generó problemas de exclusión e imaginarios sociales diferentes, porque dichas migraciones “...pueden incrementar los conflictos raciales y sociales, o la competencia por recursos, en las sociedades receptoras" (Aguirre 2000).

\section{Las migraciones internacionales}

En todas las épocas de la historia se han registrado movimientos de población y los hombres han emigrado. Los primeros fueron los grupos nómades que buscando dónde cazar y recoger frutos para su alimentación iban de un lugar a otro. Luego, cuando esos grupos humanos se asentaron, algunos individuos migraron buscando nuevas alternativas para su desarrollo, pero al mismo tiempo, el grupo recibió a otros pobladores que requerían establecerse con el fin de asegurar su subsistencia.

Con el paso del tiempo, en la Antigüedad clásica, en la época de los Descubrimientos, en el Antiguo
Régimen se registraron movimientos de población debido a múltiples factores. Sin embargo, el gran movimiento inmigratorio internacional, de Europa a América, tomó un carácter masivo a partir de la segunda mitad del siglo XIX, con la Revolución industrial, pues más de 50 millones de europeos pasaron a tierras americanas en busca de nuevas realidades políticas, sociales y económicas que mejoraran sus condiciones de vida (Norambuena 2008).

Durante el siglo XX las migraciones masivas comenzaron después de la Segunda Guerra Mundial desplazando población europea hacia otros continentes. No obstante, a partir de la década de 1970, debido a las crisis económicas mundiales, numerosos contingentes humanos de países subdesarrollados comenzaron a migrar hacia los países desarrollados convirtiendo el proceso de migración internacional en "...una estrategia de subsistencia y movilidad social" (Itzingsohn 2003), no resultando extemporáneo señalar que, por ese carácter, "...en la última década del siglo XX se haya construido la figura de la era de la migración" (Martínez Pizarro 2000:7) .

De esta manera, en los comienzos del siglo XXI los movimientos migratorios internacionales se han convertido en un proceso complejo en el que intervienen múltiples elementos y circunstancias de distinto tipo y forma. Por otra parte, cada acto de migrar, independiente de su duración, implica un conjunto de factores asociados en la sociedad de origen y en la sociedad receptora que pueden tener una connotación positiva o negativa.

Lo nuevo en este panorama del siglo XXI es que los movimientos de población están marcados por la globalización, por la creciente interdependencia entre los países de la aldea global y por los escenarios de los mercados que compiten porque la reestructuración productiva les sea favorable. El escenario descrito propiciaría la migración, la que asumiría otras modalidades de movilidad y de transnacionalización determinando que los desplazamientos de las personas sean más llamativos y complejos y que los Estados receptores den respuestas oficiales para enfrentar los numerosos desafíos que les plantea esta nueva situación poblacional.

Por otra parte, la progresiva influencia de los factores económicos, sociales y culturales de carácter mundial acerca de aquellos de carácter nacional o regional impactan desde diversos ángulos 
En el ámbito político, los cambios en la cultura inciden tanto en la política internacional como en la forma, valores, actores y mecanismos de la vida política interna de los países industrializados y en desarrollo. Así, por ejemplo, amplios flujos migratorios provenientes de otras culturas han modificado las situaciones socioculturales, políticas y económicas de muchos países europeos y de los Estados Unidos (Martínez Pizarro 2000:179).

En consecuencia, por las características que han asumido los actuales desplazamientos internacionales de población es necesario enfrentarlos con criterios globales, o al menos, regionales debido a que a nivel nacional es cada vez más difícil dar una respuesta positiva. Esta situación se entiende porque las migraciones internacionales tienen lugar al interior de un sistema de convivencia global, en el que intervienen diversos factores que no modelan un contexto coyuntural, sino que muy por el contrario son parte de la dinámica estructural de la globalización.

Los especialistas han propuesto diversas teorías para explicar el fenómeno de las migraciones internacionales en el siglo XXI. Si bien todas ellas se refieren al mismo problema, las posturas y enfoques son diferentes. En efecto, el enfoque económico neoclásico pone énfasis en las diferencias de salarios, las condiciones de trabajo, los costos de la migración agregando que este movimiento poblacional se produce por una decisión personal que trata de maximizar los ingresos. En oposición, la nueva teoría económica respecto de migración pone de relieve la suma de mercados que prima en el mercado de trabajo, entendiendo la migración como una decisión más familiar que personal. Otras teorías, como la del mercado laboral dual, asocia la migración a las necesidades estructurales de las economías industrializadas, en tanto, teoría de los sistemas mundiales liga a la inmigración al impacto de la globalización y la expansión del mercado (Massey et al. 2008).

Bajo estas condiciones, cabría preguntarse ¿qué motiva a las personas para tomar la decisión de migrar? La respuesta es compleja porque el futuro migrante debe considerar dos aspectos fundamentales: su situación personal en su país de origen y las condiciones que le ofrece el contexto de la globalización al momento de iniciar el proceso de inmigración internacional.
Con relación a la situación personal, la variable económica está en el centro de las causas de la decisión de las migraciones internacionales por la expectativa que tiene el migrante de obtener un ingreso más alto en el extranjero que en su propio país. Otras variables que ejercen una influencia importante para migrar y que no incluyen motivos económicos son la guerra, la discriminación étnica y la persecución política en el país de residencia. Además, la elección del país de destino a menudo también está influenciada por la existencia de una red de familiares y amigos que han migrado previamente. Cada una de estas variables tiene su propia dinámica, pero no excluye a cualquiera de las otras.

Respecto del contexto global, Andrés Solimano establece siete variables como determinantes de la inmigración internacional, sin que el orden presente prioridad de una sobre otra: renta per cápita o diferencias salariales, estado del ciclo económico, redes migratorias, políticas de inmigración, costos de la inmigración, diferencias culturales entre los países y distancia geográfica (Solimano 2003).

En cuanto a la renta per cápita lo más importante para el migrante es el salario esperado en la sociedad que lo acogerá porque está en relación con las remesas que podrán enviar a su familia, en caso de no migrar con ella. Esta variable se asocia a la posibilidad de encontrar empleo, lo que depende del ritmo de crecimiento que tiene el ciclo económico en el país receptor.

Las cadenas o redes migratorias presentan un valor agregado para los migrantes porque la existencia de familiares o amigos es crucial en la selección del país de destino debido a que se tiene información acerca del mercado de trabajo y características de la sociedad acogedora. Esta variable se asocia estrechamente al conocimiento de las políticas de inmigración del país receptor porque las redes podrán informar y dar testimonio atinente a dichas políticas. No obstante, el conocimiento de las políticas no es decisiva para disuadir al migrante porque le queda la posibilidad de la migración irregular.

Los costos de la inmigración así como la distancia geográfica del país de origen al de llegada constituyen factores de inhibición para la migración. La decisión de emigrar tiene diversos gastos varios, en los que se incluye: pasajes, alimentación, instalación y búsqueda de trabajo. Los inmigrantes no calificados y los que no tienen recursos económicos son a veces afectados por estos costos, ya que los 
inhiben a inmigrar. Por esta razón, en los últimos años la migración a países fronterizos tiende a ser más común que a países ubicados a mayor distancia geográfica, por lo que este factor se torna importante en relación con la dirección y el tamaño de los flujos migratorios internacionales.

Finalmente, factores culturales como la lengua, las tradiciones y las relaciones familiares también afectan los patrones de migración porque normalmente difieren entre el país receptor y el emisor y tienden a actuar como factores que afectan el tamaño del flujo de la migración internacional.

En este contexto general, la migración internacional presenta dos dimensiones; la emigración y la inmigración. La emigración se refiere a la salida de población e implica básicamente el reconocimiento, por parte del Estado, de la libertad de movimiento del individuo, en tanto que la inmigración se refiere a la entrada a un país receptor de personas que han nacido en otro lugar. No obstante, implica dos cuestiones básicas:

1. la que se relaciona con criterios y condiciones de entrada y establecimiento de residencia de extranjeros en el país receptor.

2. aquella que hace referencia a los derechos y deberes de los inmigrantes en la sociedad receptora.

Desde la perspectiva económica, la inmigración en los países receptores desarrollados resalta la dependencia en relación con el trabajo inmigrante por mantener la productividad y sostener los sistemas de seguridad social. Además, determinados sectores de la economía son altamente dependientes de la mano de obra inmigrante, y casi siempre se posicionan a favor de políticas más abiertas en lo concerniente a la inmigración (Sprandel et al. 2008). Finalmente, la inmigración internacional de mano de obra calificada mejora la competitividad de los países desarrollados y presiona por una política migratoria selectiva.

En la práctica, en los últimos años la mayor puerta de entrada legal de inmigrantes ha sido por medio de la reunificación familiar, pero también llevó a un gran aumento de la inmigración irregular.

En este sentido, el crecimiento de la inmigración internacional indocumentada ha servido como base para un discurso político que considera que los Estados han perdido el control sobre sus fronteras y que los países desarrollados están siendo invadidos por los migrantes provenientes de países en desarrollo.

A manera de ejemplo, se puede señalar que los países de América del Sur, hasta mediados del siglo XX, eran considerados tradicionales receptores de inmigración. Sin embargo, a partir de la década de 1960, la emergencia de regímenes dictatoriales en la región impulsó un movimiento de salida, dirigido principalmente hacia Europa y países vecinos.

Desde 1980 los inmigrantes sudamericanos se fueron a vivir en otros países de la propia región. En 2000, Argentina y Venezuela albergaban a 2/3 de los emigrantes latinoamericanos. Otros flujos regionales importantes son: el de brasileños al Paraguay y, más recientemente, de bolivianos en Brasil y peruanos en Chile (Arellano 2013). Otro aspecto del problema es que los migrantes eligen como sociedad receptora un país cercano, ya que

“...facilita la comunicación, por ser de cultura similar y bajo costo de viajar. Por ejemplo, los ciudadanos de Paraguay, Bolivia y Chile tienen como principal destino Argentina; en Colombia el 69\% de sus migrantes tienden a elegir Bolivia; el 71\% migrante de los nacionales de Guatemala han elegido México, y de los nacionales de Nicaragua el $91 \%$ de sus migrantes la elección es Costa Rica" (Arellano 2013:18).

El conflicto político colombiano es responsable por el mayor flujo de emigrantes de América del Sur, llegando hoy a 900.000 personas, lo que genera cierta tensión en las relaciones interestatales en la región.

Las considerables restricciones que los países desarrollados imponen a los desplazamientos de la población, frente a la total libertad de movimientos para las mercancías, el capital, los servicios, la información y las ideas suponen, quizás, la principal contradicción de la mundialización económica que la globalización ha ido articulando progresivamente. En definitiva, la globalización de la economía no viene acompañada de la globalización del bienestar y de la seguridad de la que disfrutan los países desarrollados, porque dejan fuera del desarrollo económico y social a miles de millones de personas.

La pregunta clave es ¿cómo se resolverá esta contradicción? Sin embargo, se puede suponer que, en el corto plazo, las actuales políticas migratorias y las de cooperación para el desarrollo que se están aplicando no la resolverán. 


\section{Migraciones y seguridad}

Las profundas transformaciones que trajo el mundo globalizado acentuaron aún más la relación del binomio migraciones-seguridad. La estrategia estatal respecto de migraciones tiene entre sus objetivos asegurar que las normas en materia de política de migración de ninguna manera afecten negativamente la seguridad nacional, ya sea en términos políticos, económicos, sociales u otro indicador social de la convivencia interna. Por esta razón, el proceso migratorio internacional tiene hoy diversas dimensiones de análisis y una multiplicidad de políticas públicas que consideran los Estados nacionales y los organismos internacionales.

Los estudios acerca de temas migratorios que están conectados con factores de seguridad, constituyen actualmente un espacio novedoso de reflexión académica, investigación aplicada y debate político para las distintas disciplinas sociales que desde variados enfoques teóricos y metodológicos influyen en el diseño de políticas públicas para los Estados y las sociedades (Rivera 2003).

A fines del siglo XX, el concepto tradicional relativos a seguridad sufrió cambios importantes debido al impacto de la mundialización, especialmente porque se consideraron otros aspectos relacionados con la variación de las amenazas a la seguridad lo que fue "... haciendo insostenible e insuficiente la idea tradicional de seguridad" (Rojas y Álvarez 2010: 5)

En un sector se ubicaron los países que teniendo una notable preocupación por materia de seguridad comienzan a introducir diversos calificativos, como seguridad común, cooperativa, colectiva, comprehensiva, que se alinean con una visión más centrada en la cooperación bilateral o multilateral. En otro sector,

“...surgen críticas a una concepción estrecha y ortodoxa para incluir nuevas amenazas multidimensionales: económicas, poblacionales, del medio ambiente, de movimientos de personas, de redes criminales o de violaciones -a veces masivas- de derechos humanos" (Herrera y Artola 2011:30).

En el caso de América Latina, por ejemplo, las discusiones concernientes a este problema de las amenazas multidimensionales, que se hicieron a nivel de la Organización de Estados Americanos (OEA), en su reunión de México en 2003, si bien no incluyeron directamente los fenómenos migratorios, estos se conectaron con la trata de personas como se puede inferir al leer el artículo $\mathrm{N}^{\circ} 4$, letra $\mathrm{m}$, contenido en la Declaración sobre Seguridad en las Américas (OEA 2003).

Por otra parte, también en América Latina se presentan varios dilemas y análisis de seguridad nacional. No obstante lo que es claro y preciso es que este tipo de estudios

“...están dejando de ser un terreno exclusivo de investigación para estamentos militares, policiales o judiciales para convertirse en un campo deliberativo donde participan múltiples actores sociales e institucionales. Por ejemplo, muchos ámbitos de la política exterior, la economía regional y la gestión pública local están vinculados a temas de seguridad porque existe una serie de factores particulares y generales, nacionales como internacionales que afectan a la población en conjunto" (Rivera 2003:1).

En esa perspectiva, los diversos gobiernos tratan esencialmente de distinguir o de establecer diferencias entre la migración legal de la ilegal, para observar situaciones migratorias regulares o irregulares, porque esta última es la que causa una mayor preocupación a los gobiernos de los países receptores de migrantes porque es la que regularmente se asocia a problemas y riesgos de seguridad.

Teniendo presente estas cuestiones, los Estados aplican diferentes políticas de seguridad respecto de las migraciones internacionales.

"El objetivo central de la política de seguridad de un Estado debe ser, para los realistas y neorrealistas, disponer de todos los medios indispensables, así como de los recursos necesarios para preservar el interés de la nación, pues con ello se logrará mantener la integridad y librar de las amenazas a aquellos intereses prioritarios del Estado" (Orozco 20:166)

En la actualidad los organismos internacionales, los Estados y las comunidades académicas tienen como interés estudiar las conexiones existentes entre el mundo globalizado y las diferentes dinámicas migratorias frente a la llamada migración irregu$\operatorname{lar}^{2}$, teniendo como especial objetivo no vulnerar 
los derechos humanos y facilitar la entrada de los extranjeros cuya presencia es deseada e identificar y disuadir la entrada de extranjeros no deseados, particularmente aquellos que representen riesgos para la seguridad interna en términos políticos, económicos y sociales.

Considerando que las migraciones internacionales de la actualidad se han transformado en una estrategia de subsistencia y movilidad social, es en este sentido que este fenómeno migratorio se caracteriza no solo como una opción de movilidad social ascendente, sino también en muchos casos como la única posibilidad de asegurar mínimamente la propia subsistencia. Sin embargo este carácter choca con la adopción de políticas públicas que consideran a los flujos migratorios de migrantes como un tipo de población susceptible de vigilancia y control y, además, de estar sometida a la aplicación de las políticas de seguridad (Itzingshon 2003).

A pesar de que los flujos migratorios existen desde hace décadas, hoy más que nunca esas distintas lógicas de movilidad humana están sujetas a dos tipos de problemas. En primer lugar, aquellos signos discriminadores y excluyentes y los imaginarios racistas que están presentes en las comunidades de las sociedades receptoras y, en segundo lugar, la aplicación de medidas y acciones preventivas que se amparan en determinadas percepciones de seguridad nacional que atentan contra los derechos humanos de los migrantes y provocan tensiones en las políticas del sistema internacional (Rivera 2003).

Es en este nuevo contexto de globalización, de tendencias excluyentes e integradoras de continuidades y rupturas, que se inscriben los grandes movimientos migratorios internacionales, en donde la pugna por un libre movimiento de los factores, tanto de producción y de capital, como de bienes e información, se ve contrariada por la restricción al derecho de millones de personas de moverse (Boggione 2012).

Es curioso, entonces, que el problema se presente en tiempos de la mundialización de la economía y tenga dos caras. Por un lado, el desarrollo económico de los países industrializados requiere de mano de obra barata y capital humano avanzado y, por otro, en esos mismos países, que son los receptores del flujo migratorio, aumentan las “...ideas de riesgo, vulnerabilidad y amenaza para las sociedades receptoras que siguen manteniendo esos tradicionales conceptos derivados de las teorías clásicas de la seguridad" (Rivera 2003:2).
Las autoridades políticas, tanto en los países expulsores como receptores de población, han establecido políticas y dictado leyes reguladoras de los movimientos migratorios para el control y supervisión de quienes ingresan a su territorio, teniendo presente que la legislación migratoria nacional favorezca la inmigración de quienes se consideran mano de obra altamente calificada, lo que representa un activo seguro para sus economías, y tienda a restringir la entrada de migrantes libres y voluntarios que tienen la necesidad de trasladarse a lugares donde existen mejores oportunidades de trabajo.

A pesar de que no existen instrumentos internacionales o regionales acerca de derechos humanos que otorguen expresamente a los extranjeros el derecho a ingresar a un país que no sea el suyo, las condiciones del mundo globalizado del siglo XXI han llevado a asociar en forma directa los flujos migratorios con las prioridades de seguridad de los países receptores.

Entonces, se puede preguntar ¿Por qué este tipo de problemas genera tensiones políticas entre el sistema de derechos humanos, las migraciones internacionales y las políticas de seguridad?

Desde el punto de vista de la seguridad internacional hay dos posiciones teóricas. En primer lugar está el enfoque de seguridad tradicional que establece una estrecha relación entre la seguridad y lo militar, por lo que se hace referencia exclusivamente a la seguridad del Estado en un sentido westfaliano. En segundo lugar, están los enfoques que intentan generar nuevas herramientas teóricoconceptuales para poder dar cuenta de aquellos fenómenos que adquieren una singular relevancia en este momento histórico, como el (re)surgimiento de los nacionalismos y las identidades nacionales, las problemáticas económicas y ambientales, la vuelta a los conflictos religiosos o la inmigración internacional (Boggione 2012).

De esta segunda posición y siguiendo a Barry Buzan, la Escuela de Copenhague considera que el concepto de seguridad se establece cuando un representante del Estado declara una condición de emergencia reclamando el derecho de usar cualquier medio que sea necesario para bloquear el desarrollo de la amenaza (Waever 1995).

En términos generales y frente a los problemas que plantean los flujos migratorios la respuesta parece simple, porque en el caso de América, se genera una problemática denominada seguritización. 
La seguritización es un proceso discursivo y político que construye una fórmula intersubjetiva al interior de una comunidad política, con el fin de tratar algo "...como una amenaza existencial a un objeto de referencia valorado, para así hacer un llamado urgente sobre medidas excepcionales, y hacerle frente a las amenazas" (Brauch:283)

Sin embargo, esta conceptualización no es utilizada por los que proponen las políticas públicas, razón por la que la seguritización es un proceso que está constituido por diversas medidas que se relacionan con el campo de la seguridad. En teoría, cualquier tema puede ser localizado en el espectro que va desde la no politización, lo que implica que no es materia de debate público o que implique toma de decisiones. Luego, se puede entrar a la fase de politización, es decir, el tema es parte de la política pública y requiere una decisión gubernamental, para finalmente, alcanzar el estatus de seguritización, donde el tema aparece como amenaza a la supervivencia, demandando medidas de emergencia y justificando acciones por fuera de los cánones normales de los procedimientos políticos.

$\mathrm{Si}$ se toma como ejemplo el tema de las migraciones fronterizas es preciso indicar que siempre los migrantes han sido controlados con relación a la seguridad estatal. Sin embargo, las deliberaciones actuales de los gobiernos se centran en las posibilidades de verificar con antelación las características personales de los migrantes y de realizar esfuerzos más meticulosos para impedir que las personas identificadas como posibles amenazas a la seguridad crucen las fronteras.

Otros temas o problemas que afectan a los Estados pueden incluirse dentro de las políticas de securitización. Por ejemplo, problemas sociales o económicos normales, que se relacionan con el consumo de drogas mediante flujos migratorios, o las corrientes migratorias que en su interior tienen perfiles delincuenciales porque están asociadas con el tráfico de personas, lógicamente van a observarse como una amenaza a la seguridad nacional.

Bajo esa premisa, en el problema tripartito que existe en torno al tema migraciones internacionales, derechos humanos y seguridad se agregan principios del régimen internacional de protección a los derechos humanos, que exige cooperación entre países con distintos niveles de poder y desarrollo, y las políticas internacionales de seguridad que vulneran esos mismos derechos en una suerte de lógica perversa que argumentan los actores que construyen intereses tanto de las políticas de seguridad nacional como las del régimen internacional (Rivera 2003).

Uno de los efectos de mayor peso después del 11 de septiembre de 2001 fue que se amplió el concepto de seguridad nacional y regional y se puso en la mira los movimientos migratorios limitando los derechos humanos de los migrantes forzados, ya sea refugiados o asilados, aunque también se asoció a esta nueva concepción la desarticulación de los grupos que apoyaban la inmigración ilegal e indocumentada y el tráfico de drogas.

Otra seña particular que se asocia actualmente al fenómeno de las migraciones internacionales, más allá del importante tema de la seguridad, es el incremento de las migraciones "irregulares" y de las migraciones "indocumentadas", cuyos rasgos definen a la actual etapa de las migraciones, y que debido a la clandestinidad y permanente movilidad de este tipo de flujo migratorio no es posible cuantificarlo a nivel global.

En este contexto, se han elaborado alternativas de análisis y de construcción de políticas públicas que tienen como norte la idea de seguridad humana antes que la nacional. En ese sentido, las migraciones internacionales deberían ser observadas con otros parámetros, tanto en los países emisores como en los receptores.

\section{A modo de conclusión}

La migración internacional, como fenómeno social, como problema para el migrante, la sociedad receptora y la emisora y como tema de estudio, adquiere una importancia cada vez mayor en los inicios de este milenio en el que la globalización amenaza con borrar las fronteras nacionales para la economía, el mercado, la información, los conocimientos y la tecnología.

La circulación migratoria abarca a todas las regiones del planeta. Se producen tanto migraciones intrarregionales, entre países fronterizos o cercanos, con patrones culturales similares, como migraciones extrarregionales en donde el migrante cambia no solo de espacio geográfico sino también de espacio cultural. A esto se añade que en algunos países del mundo se presentan actitudes negativas hacia los migrantes, que en muchas ocasiones sienten el rechazo de los nacionales y son objeto de discriminación y abuso.

Los empresarios desean aumentar su competitividad contratando mano de obra barata, proveniente 
de países con más bajos niveles de vida, frecuentemente en condiciones de ilegalidad, que aceptan trabajar en condiciones que algunos nacionales no aceptarían.

La migración irregular en la primera década del siglo XXI continúa siendo una de las manifestaciones más preocupantes de los crecientes flujos migratorios mundiales que concita la atención por igual de los países emisores y los receptores, aunque el tipo de preocupación sea distinto para cada uno de ellos. Mientras los países emisores tienen en cuenta los riesgos y las consecuencias de este tipo de migración para sus nacionales, las sociedades receptoras se empeñan en regularizar a los que ya están dentro o de impedir que entren los que lo intentan.

En suma, los migrantes internacionales constituyen un riesgo económico para el mercado de trabajo interno en los países receptores y no necesariamente un riesgo para la seguridad nacional y estabilidad democrática, a menos que sean promovidos o financiados por redes de trata de personas, redes de prostitución, o sean activos participantes del tráfico de drogas o pertenezcan a las filas del crimen organizado transnacional.

\section{Referencias Citadas}

Aguirre, M.

2000 El debate sobre la seguridad en la globalización. Fuerzas Armadas y Sociedad FASOC 15: 3-12, FLACSO. Santiago. Chile.

Aliaga Sáez, F.

2012 Imaginarios migratorios y geopolítica en sociedades postmodernas. Imagonautas. 1: 2-20. Santiago de Compostela. España.

Arellano, P.

2013 Características y desafíos de la migración para la seguridad social en la región latinoamericana. Revista Chilena de Derecho y Ciencia Política. 4. 1: 15-42. Universidad Católica de Temuco. Temuco. Chile.

Beck, Ulrich

1998 ¿Qué es la globalización? Falacias del globalismo, respuestas a la globalización. Paidós, Barcelona

Boggione, $\mathrm{S}$.

2012 Globalización, Migraciones y Seguridad. Revista Gestión de las Personas y Tecnología. 13: 18-29. USACH, Facultad Tecnológica. Santiago

Brauch, H.G.

2009 Seguritización del espacio y del objeto de referencia. Reconceptualizar la seguridad en el siglo XXI, editado por Úrsula Oswald Spring y Hans Günter Brauch, pp. 283-328. Coedición Centro de Ciencias de la Atmósfera-Centro de Investigaciones Multidisciplinarias en Ciencias y Humanidades. México.

Braudel, F.

1982 Civilización material, economía y capitalismo siglos XVXVII. Tomo III El tiempo del mundo. Alianza Editorial. Barcelona.

Bravo, G.

2004 Economía, comercio y mercados en América del Sur en el último siglo colonial. Relaciones interregionales. Los Caminos del Mercosur. Historia Económica Regional. Etapa Colonial, editado por Hernán A. Silva, pp. 67-90. Instituto Panamericano de Geografía e Historia. México.

Castells, M.

2005 Globalización, desarrollo y democracia: Chile en el contexto mundial. FCE. Santiago

Comisión Económica para América Latina (CEPAL)

2002 La migración internacional y la globalización. Globalización y desarrollo. http://www.cepal.org/es/publicaciones/2724globalizacion-y-desarrollo (14 agosto 2015).
Comisión Mundial sobre la Dimensión Social de la Globalización (CMDSG).

2004 La Dimensión Social de la Globalización. http://www. ilo.org/public/spanish/wcsdg/docs/report.pdf (15 agosto 2014).

Dehesa, G.

2000 Comprender la globalización. Ed. Alianza.

Diccionario de la Real Academia Española de la Lengua (DRAE) $201423^{a}$ Edición. http://lema.rae.es/drae/?val= globalizaci\%C3\%B3n (8 agosto 2014)

Ellwood, W.

2007 Globalización. Intermón Oxfan Ediciones. Barcelona.

Herrera-Lasso, L. y Artola, J.B.

2011 Migración y Seguridad: dilemas e interrogantes. Migración y Seguridad: nuevo desafío en México, editado por Natalia Armijo Canto. 1. 11-34. CASEDE. México.

Itzingsohn, J.

2003 Migración, globalización y geopolítica. Anuario Social y Política de América Latina y el Caribe 6: FLACSO.

Lombardo P.

2006 La seguridad internacional en las relaciones exteriores de América Latina: elementos para una discusión. Revista de Estudios Internacionales. Vol. 39. 155: 71-79. Universidad de Chile. Santiago.

Martínez Pizarro, J.

2000 La migración internacional y el desarrollo en la era de la globalización e integración: temas para una agenda regional. Serie Población y Desarrollo 10: Santiago.

Massey, D., Arango, J., Graeme, H., Kouaouci, A., Pellegrino,

A. y Taylor, E.

2008 Teorías de Migración Internacional: Una revisión y aproximación. Revista de Derecho Constitucional Europeo. ReDCE. 10: 435-478. Universidad de Granada. Granada. España.

Mendizábal, A.

2010 La dimensión tecnológica de la globalización. XII Reunión de Economía Mundial. Santiago de Compostela, 2010, http://www.ilo.org/public/spanish/wcsdg/globali/ (20 agosto 2014).

Moneta, C.J.

2000 La dimensión cultural de la globalización: una perspectiva desde los Estados-Nación. América Latina en tiempo de globalización II: cultura y transformaciones 
sociales, coordinado por Daniel Mato, Ximena Agudo e Illia García. Universidad Central de Venezuela-UNESCO. Caracas.

Norambuena, C.

2008 Revisión Histórica de los Movimientos Migratorios en Chile. Historiadores Chilenos Frente al Bicentenario, editado por Luis Carlos Parentini, pp. 329-336. Cuadernos del Bicentenario. Santiago.

Organización de Estados Americanos (OEA)

2014 Conferencia Especial sobre Seguridad. México, 27-28 de octubre de 2003. https://www.oas.org/es/ssm/CE00339S03. pdf (19 agosto 2014)

Orozco, G.

2006 El concepto de seguridad en la Teoría de las Relaciones Internacionales. Revista CIDOB dÁffers Internacionals. 72: Barcelona

Rivera Vélez, F.

2003 Migraciones y Seguridad. Aportes Andinos: 23: 1-7. Universidad Andina Simón Bolívar. Quito. Ecuador.
Smith, A.

1992 Investigación sobre la naturaleza y causa de las riquezas de las naciones. FCE. México.

Solimano, A.

2003 Globalización y migración internacional: la experiencia latinoamericana. Revista Cepal 80: 55-72.

Sprandel, M., Rocha Reis, R. y Fusco, W.

2008 Las migraciones internacionales en las Américas. Costa Rica.

Trigo Portela, J. Tremosa i Balcells, R. y Viñeta, S.

2003 L'empresa catalana en l'economia global. Papers d'economia industrial 19: 135. Generalitat de Catalunya. Barcelona. España.

Waever, O.

1995 Securitization and Desecuritization. On Security, editado por R. Lipschutz. Columbia University Press. Nueva York.

Zolo, D.

2000 Cosmópolis. Perspectiva y riesgos de un gobierno mundial. Ed. Paidós, Barcelona.

\section{Notas}

Ejemplo de estos bloques económicos son el MERCOSUR 2 y la UNIÓN EUROPEA.
Este concepto se aplica a los migrantes que ingresan o permanecen en un país sin autorización. 
ANDROS IMPRESORES

www.androsimpresores.cl 

